\title{
PUBLICIDAD Y CONSUMO EN THEY LIVE. ANÁLISIS CRÍTICO SOBRE LA IDEOLOGÍA PUBLICITARIA
}

Javier García López: Universidad a Distancia de Madrid. España.

javier.garcia@udima.es

\section{RESUMEN}

El trabajo que se presenta plantea un estudio cultural acerca del efecto de la ideología de la publicidad y del consumo en las sociedad contemporáneas a través de la película They Live (Están vivos). La pieza audiovisual tratada pone de manifiesto que vivimos en sociedades determinadas por un sistema de producción y consumo crecientes en las que la publicidad, como herramienta de las instituciones, seduce a los ciudadanos con el objetivo de mantener el statu quo. Se utiliza un método de investigación fundamentado en el análisis del relato audiovisual, por medio de un minucioso examen de los componentes de la narración. A través de una historia de ficción, la película desarrolla una descripción verosímil sobre cómo la ideología sistemática, amplificada por la publicidad, configura una pauta velada de pensamiento y de acción social al servicio de empresas e instituciones. El protagonista de la película, John Nada, mostrará que la disidencia implica un violento y doloroso camino necesario para conseguir la libertad.

PALABRAS CLAVE

Publicidad - Consumo - Ideología - They live - Disidencia - Libertad

\section{ADVERTISING AND CONSUMPTION IN THEY LIVE. CRITICAL ANALYSIS ON AD IDEOLOGY}

\begin{abstract}
The work presented is a cultural study on the effect of the ideology of advertising and consumption in contemporary society through the film They Live. The

1Javier García López: Doctor en Comunicación, licenciado en Publicidad y master en Crítica y Argumentación Filosófica. Actualmente es Profesor Contratado Doctor en el departamento de Comunicación de la Universidad a Distancia de Madrid.
\end{abstract}


audiovisual piece analyzed shows that we live in societies determined by a system of production and consumption growing do advertising as a tool of the institutions, seduces citizens with the aim of maintaining the statu quo. It use a research method based on analysis of audiovisual narrative is used, through an examination of the components of the story. Through a fictional story, the film develops a plausible description of how the systematic ideology, amplified by advertising, creates a hidden pattern of thought and social action in the service of companies and institutions. The main character of the film, John Nada, announces that dissent involves a violent and painful path that is necessary to achieve freedom.

\section{KEY WORDS}

Advertising - Consumption - Ideology - They live - Dissent - Freedom

\section{INTRODUCCIÓN}

Las sociedades actuales están determinadas por un sistema socioeconómico de producción y consumo crecientes. Casi nadie pone en duda que el consumismo es una práctica social mayoritaria. Los individuos desean objetos y servicios que los productores del sistema ponen en circulación. Esos deseos pueden convertirse en necesidades en el momento en el que se sienten como carencias que han de satisfacerse para alcanzar un alto grado de bienestar. En este contexto, la publicidad se ha instituido como una herramienta al servicio de empresas y organismos, públicos o privados. Como ya han planteado numerosos autores (Williamson, 1978; Ibáñez, 1989; Scott, 1994; Hirschman, 2003; San Nicolás, 2006; Hellín, 2007; Eguizábal, 2009; Grupo Marcuse, 2009), la publicidad es un artefacto comunicativo muy potente por medio del cual los grupos productores consolidan sus posiciones hegemónicas y perpetúan el funcionamiento del engranaje.

Hablamos en este ambiente de publicidad en un sentido amplio. Un sentido de lo publicitario que acepta como tal a cualquier forma de comunicación persuasiva masiva al servicio de un dispositivo de producción y consumo que no acepta una pausa en su crecimiento. En muchos casos, los relatos de la publicidad pueden llegar a confundirse con los argumentos propagandísticos, que suelen relacionarse más con las acciones políticas o religiosas. De cualquier modo, Ibáñez (1989) ya explicó a finales del siglo pasado que la publicidad y su discurso actúan como la religión y calan en los individuos como una pauta imperante de pensamiento y de acción. Igualmente, Williamson (1978) argumentó que la publicidad posee una especial competencia institucional para crear un determinado significado al servicio del sistema. Los seres humanos suelen crearse una visión del mundo que los rodea fuertemente influida por los relatos que desarrolla la publicidad. Y en este contexto no es relevante la distinción entre lo imaginario y lo real, puesto que a través de la publicidad cualquier argumento que parte del sistema se instituye como real. No obstante, no podemos perder de vista que ese proceso por medio del cual la publicidad crea pautas de pensamiento y de conducta para un consumo y una producción crecientes no es percibido por la mayoría de personas. 
La sociedad en la que vivimos se fundamenta en la preponderancia económica sobre otras facetas sociales. Esta economía se sustenta en una idea que, en los términos en los que se utiliza, proviene del siglo XVIII: la idea de competencia, bien estudiada por Adam Smith y desarrollada posteriormente por David Ricardo y otros. Se supone que existe una competencia perfecta, si bien ciertos autores prefieren hablar de una economía que tiende o pretende alcanzar una competencia perfecta. Otros autores prefieren hablar de una economía de libre mercado, aunque se considera mucho más acertado el argumento que nos dice que actualmente nos movemos en una economía de acumulación de capital. En este contexto, la publicidad actúa como una herramienta ineludible y como motor económico del sistema. Según argumentan Arens, Weigold y Arens (2008: 31-32), "las personas y organizaciones tienden a actuar por su interés personal [...]. Siempre desean más por menos". Según otros autores, esta idea se sustenta en la noción de naturaleza de la competencia económica. Por tanto, es, como poco, filosóficamente discutible, ya que en la historia de la humanidad han existido otras organizaciones económicas e, incluso, de mercado, que no han acudido a las ideas de competencia y de acumulación del capital para su funcionamiento; estas otras formas económicas también han sido "naturales" (Polanyi, 2014). Pero, ¿qué función cumple la publicidad en este contexto? En economías congestionadas como la nuestra, donde existen multitud de vendedores, millones de compradores y las instituciones estatales han reducido su papel económico, la publicidad sirve para decantar la balanza hacia unos pocos. Es decir, la publicidad ayuda a las empresas y organismos a diferenciarse (simbólicamente, imaginariamente) y a atraer a potenciales consumidores. Todo gira en torno a la idea de consumo (y de producción, proceso que es inherente). Las empresas e instituciones necesitan entrar en las cabezas de la gente y ocupar un hueco en su memoria, con el objetivo de que estos individuos recuerden la marca, el producto o el servicio y lo compren, o al menos lo deseen de manera imperiosa.

En este sentido, They Live (1988), de John Carpenter, es una cinta cinematográfica que describe el modo en el que las sociedades contemporáneas han abandonado la crítica al sistema de producción y consumo crecientes y se han abonado a sus prácticas publicitarias, tal y como se ha propuesto. Un ejemplo de hipercine "portador de una acentuada tendencia a reflexionar sobre sí mismo, sobre el mundo, sobre el individuo" (Lipovetski y Serroy, 2009: 213). A pesar de que ya han pasado casi treinta años del estreno del film, They Live (Están vivos, en español) desarrolla una descripción válida de la sociedad actual, tal y como propone Zizek (2012). A continuación se propone un análisis pormenorizado de la cinta cinematográfica, que ofrece una interesante descripción de la sociedad del momento, según su director y guionista, John Carpenter.

\section{OBJETIVOS}

El objetivo principal de este estudio es el análisis de la sociedad publicitaria y del consumo en la que nos movemos en la actualidad, representada en la película They Live (1988). Los objetivos secundarios de esta investigación son: 
- El estudio de las relaciones existentes entre el concepto de ideología y los conceptos de publicidad y de consumo.

- El análisis de los componentes del relato audiovisual y su vinculación con la realidad actual: perspectiva de los personajes, ambientes creados, acción narrativa y tono del relato.

- El estudio cultural sobre los modos de disidencia social o de la acción humana crítica con el sistema imperante de producción y consumo crecientes, representados por John Nada, el protagonista de la película.

\section{MÉTODO DE ANÁLISIS}

La investigación desarrolla un análisis completo de la narración audiovisual de la película They live (Están vivos, 1988). El método de análisis está sustentado en un minucioso examen cualitativo del relato audiovisual. Se han estudiado los parámetros narrativos puestos en marcha en la película, con el objetivo de intentar interpretar la perspectiva cultural publicitaria que despliega la cinta cinematográfica. El argumento central del film nos habla sobre la relación de la publicidad y el consumo en las sociedades contemporáneas; y para ello acude a una representación de la realidad que bebe, a su vez, de otros productos cinematográficos anteriores. Por ello, es importante atender a la historia, a las tramas y a las relaciones que se establecen entre los personajes, poniendo especial atención al personaje principal, John Nada. El concepto central de la película, como nos muestra Zizek (2012), es la ideología y su relación con la publicidad y el consumo. Por tanto, se ha de desarrollar un análisis crítico del relato que nos ayude a entender las diversas conexiones generadas entre los componentes de la narración (Thompson, 1988: 359-383).

De modo que, para poner en marcha el estudio cualitativo del relato audiovisual, hemos analizado los siguientes parámetros o componentes narrativos de They Live:

- Construcción de los personajes:

- Definición de personajes: principalmente se atiende a la caracterización de los personajes, poniendo especial atención al personaje principal, John Nada, quien vehicula la trama central. Por tanto, se analiza principalmente su personalidad y su carácter, su presencia física, la forma en la que aparece en la escena y la acción que desempeña.

- Relaciones entre personajes: se trata de las relaciones que se crean entre los distintos personajes principales. Como hemos comentado, al ser una película en la que el argumento principal viaja siempre junto al protagonista, el análisis explícito del personaje principal y su relación con los personajes secundarios es fundamental para extraer conclusiones en 
torno a la crítica de la ideología de la publicidad y del consumo en las sociedades contemporáneas.

- Componentes de la narración:

- Cosmovisión del protagonista: la visión del protagonista se desprende del análisis de su relación con el entorno y con los demás protagonistas. La cosmovisión del protagonista será central para entender el argumento de la historia cinematográfica y para comprender el sentido sociocultural que pretende infundir el director.

- Ambientes: hacemos alusión preferentemente al cronotopo, como constructo imaginario en el que confluyen las ideas de espacio y tiempo (García-López y Hellín, 2014: 759-769).

- Estructura de la acción: en esta categoría analizamos fundamentalmente cómo se desenvuelven y relacionan las categorías anteriores de la narración y cómo se gestionan el tiempo y el espacio dentro del relato. Atendiendo a la naturaleza de la película, se analiza especialmente el carácter distópico del relato, ya que lo que se muestra es una sociedad ficticia indeseable, si bien la intención es la de acercar lo máximo posible la historia a la descripción de la realidad contemporánea.

- Tono del discurso: el tono es el carácter del discurso, el matiz dramático que va a ayudar en la construcción de la perspectiva sociocultural del film; el tono nos ofrece información sobre el modo intelectual, ético-moral y sociopolítico del relato.

Todos los componentes de la narración analizados, atendiendo a la descripción desarrollada de cada uno de ellos, proporcionan información valiosa sobre cómo se relacionan los personajes, sobre la influencia del contexto o del ambiente en el que se relacionan y sobre los efectos de sus conductas. Como se puede percibir, en todo momento se está desplegando un análisis crítico de la narración en el sentido de Thompson (1988) y de Bordwell (1995), una reflexión acerca de las potencialidades ideológicas de la publicidad y del consumo en las sociedades sustentadas en la producción y el consumo crecientes.

\section{RESULTADOS Y DISCUSIÓN}

They Live (Están vivos, 1988) es una película considerada de cine independiente o de autor, escrita y dirigida por John Carpenter y producida por Larry J. Franco. Cabe destacar la curiosidad de que Carpenter utilizó un pseudónimo, Frank Armitage, para el rol de guionista. Desde el punto de vista de las grandes producciones cinematográficas de Hollywood, They Live supuso un estrepitoso fracaso, ya que la recaudación inicial en taquilla fue muy baja durante las ocho semanas en las que 
estuvo en cartel. Cuando salió en formato VHS, para uso doméstico, la recaudación fue mayor y equilibró de algún modo los gastos iniciales. La película tuvo alguna nominación a premios considerados menores dentro del espectro cinematográfico; entre ellos, cabe resaltar la nominación de mejor película para el Fantasporto International Fantasy Film Award y dos nominaciones a los Saturn Awards, en las categorías de mejor música y mejor película de ciencia ficción. A pesar de todo ello, actualmente They Live cuenta con una buena valoración dentro del ámbito de los críticos de culto.

La cinta cinematográfica entra dentro de los géneros thriller y ciencia ficción (como se ha adelantado, puede percibirse de un modo explícito el carácter distópico del relato). Se trata de una historia basada en un relato de Ray Nelson llamado Eight O'clock in the Morning (1963) y en la historieta Nada (1986), una adaptación del relato anterior que se puede ver en el número 6 de la saga de cómic Alien Encounters. La historia del film se centra en la figura de John Nada, su protagonista, interpretado por Roddy Piper. Llama la atención el apellido del personaje principal, Nada (se utiliza el apelativo en español en la versión original, quizá para encubrir de algún modo el significado explícito), que hace alusión a la inexistencia de criterio crítico en la mayoría de ciudadanos contemporáneos. Todo el argumento se centra en las vivencias de John Nada, una persona que no tiene trabajo ni casa donde vivir, un paria del mundo posmoderno. La trama comienza cuando Nada encuentra un trabajo de albañil en el oeste de Estados Unidos, en Los Ángeles.

El núcleo dramático se desencadena cuando John Nada se pone unas gafas que encuentra en una caja abandonada. Pronto se percata de que dichas gafas descubren el velo ideológico que cubre el pensamiento de las personas, el modo de conocer el mundo. La visión que proporcionan las gafas dejan ver la intención de los poderes hegemónicos de la sociedad: el interés crematístico. Además, con ellas John Nada se da cuenta de que quienes manejan los hilos de la economía y de la política son, en realidad, extraterrestres. Nada se erige en un disidente activista sociocultural. La cosmovisión de Nada se ve alterada por las gafas y ya no podrá creer en el statu quo. El protagonista siente la necesidad de abrir los ojos a los demás ciudadanos, quienes están encandilados por los mensajes publicitarios que inundan la ciudad. De hecho, toda manifestación cultural contiene un mensaje publicitario oculto relacionado con la producción y el consumo crecientes. Los extraterrestres ambicionan convertirse en una especie superior en la Tierra y para ello necesitan hacer dóciles a los humanos, precisan generar un individualismo extremo que produzca mentes planas, cerebros esclavos. No obstante, se puede advertir el tono satírico de la obra, que intenta realizar una descripción de las sociedades posmodernas, ancladas en el individualismo. Se trata de un producto cinematográfico que nos habla sobre la publicidad como una herramienta sistemática para la promoción del consumo creciente, que se sustenta, a su vez, en la producción exponencial dentro de un engranaje socioeconómico neoliberal.

\subsection{John Nada, un disidente con gafas}


La formación de los personajes es sencilla desde la perspectiva de la construcción de la narración audiovisual. No obstante, los personajes principales revelan su personalidad desde el inicio; el espectador no ha de esforzarse en la caracterización de ningún personaje. Se puede argumentar que esta película simplifica el eterno debate entre la importancia de la trama y de los personajes. Es así porque la trama se configura en la construcción propia del personaje principal. Como explica McKee (2002: 131), "no podemos valorar qué es más importante, si la estructura o los personajes, porque la estructura es sus personajes y los personajes son la estructura".

Como se ha explicado, John Nada es el protagonista de la película, quien vehicula todo el argumento. El protagonista es el portador del sentido anticapitalista de la trama. El personaje de Nada se forja en su activismo antipublicitario por medio de las gafas, que le hacen desvelar la pauta ideológica, una marca que es inherente a todo relato de la publicidad y del consumo. El personaje principal es un auténtico vagabundo, un loser que no tiene ni hogar ni trabajo. Al encontrar las gafas y darse cuenta del mundo que hay detrás de telo ideológico de cualquier conducta propia del sistema económico imperante, John Nada intentará salvar a la humanidad. Estamos ante una especie de forja del héroe, como explica Sánchez-Escalonilla (2009: 136). Podemos asegurar que John Nada es un protagonista en toda regla, siguiendo las consideraciones de Truby (2009: 79), para quien el protagonista "es la persona que tiene el problema central y el que impulsa la acción en el intento de resolver el problema". Y todo ello lo lleva a cabo Nada con los obstáculos propios de su intento de redimir a sus conciudadanos, con las debilidades y necesidades creados por el propio sistema, por las redes corruptas de la maquinaria consumista que se muestran en la narración.

Al comienzo, el protagonista se apoya en su amigo Frank Armitage, interpretado por Keith David, un tipo sencillo que le ayuda a encontrar cobijo. Todo transcurre con normalidad hasta que Nada encuentra las gafas, que son el detonante de la trama. Las gafas le permiten ver un mundo en blanco y negro, un mundo más real del que había vivido hasta el momento, a pesar de las contrariedades que había tenido que soportar en su vida. Las gafas son la herramienta que posibilita la crítica, las gafas dan lugar a decodificar un mundo manejado por seres poderosos que utilizan los medios de comunicación y la publicidad para adormecer a la masa. Cuando Nada comienza a actuar en contra del sistema, todos los personajes que lo rodean rechazarán su conducta en defensa de un supuesto estado de bienestar que anhelan, ya que ni siquiera viven en condiciones reales de felicidad.

La relación entre John Nada y Frank Armitage, su amigo, es imprescindible para comprender el desenlace de la trama. En una de las secuencias, Nada intenta explicarle a Armitage lo que sucede con las gafas. Sin embargo, Armitage no le cree. Aún así, Nada, que se ha convertido en un fugitivo de la sociedad, intenta ponerle las gafas a la fuerza a su amigo. En ese momento comienza una de las escenas de lucha más importantes de la historia del cine, como argumenta Zizek (2012); una escena que dura ocho minutos y que algunos autores han comparado con otras escenas violentas como la protagonizada por John Wayne y Victor McLaglen en The Quiet 
Man (Swires, 1988). Tras la pelea, Nada consigue ponerle las gafas a Armitage, quien entiende todo aquello que Nada le había explicado sobre la esencia publicitaria del sistema sociocultural. Ambos emprenderán a partir de ese momento un activismo conjunto en contra de la manipulación del sistema. Aunque no lo tendrán fácil, ya que son perseguidos por los defensores de los alienígenas, garantes del capitalismo.

Nada y Armitage pronto comprenderán que los extraterrestres pretenden controlar la Tierra para agotar sus recursos, lo que causa un calentamiento global ineludible. En el momento en el que destruyan la Tierra, los alienígenas acometerán otro viaje para controlar otros planetas habitables. Esta revelación que se produce a través de Nada y de Armitage llama poderosamente la atención, ya que es una constatación temprana de lo que ocurriría posteriormente, durante las dos primeras décadas del siglo XXI que estamos experimentando: sobrepoblación, calentamiento global, agotamiento de recursos, generación de desigualdades. Se puede argumentar que Nada y Armitage están anunciando la situación que vivimos en la actualidad; es decir, una crisis ecológica, una planetaria desigualdad social creciente y los desafíos planteados por la tecnociencia (Riechmann, 2014).

\subsection{They Live como crítica del sistema publicitario y de consumo}

Los componentes de la narración de They Live ponen de manifiesto que los medios de comunicación y las herramientas publicitarias de nuestro sistema capitalista actúan como lenguajes garantes de lo que debe ser. Tanto medios de comunicación como publicidad son estructuras persuasivas que seducen a los ciudadanos y les determinan en sus pensamientos y en sus conductas; se puede decir que funcionan como vehículos transmisores de las creencias del sistema sociocultural contemporáneo (Ewen y Ewen, 1982). Se trata de una especie de retórica publicitaria que impregna cualquier ámbito sociocultural y que es utilizada por los Estados y por las empresas poderosas para anclar los comportamientos sociales en el consumo imparable. Para ello, emplean la estrategia de la seducción, de la felicidad alcanzable, aunque las condiciones reales de existencia de la mayoría de humanos diste mucho de los ambientes y personajes que se anuncian. Podemos hacer un paralelismo entre lo que la película argumenta y lo que explicó Weil sobre el poso publicitario de los países sustentados por el capitalismo: "el Estado es un asociado civil y baja de su pedestal: renuncia a ser solamente normativo e imponer conductas a cambio de invitar a actitudes o comportamientos"' (Weil, 1992: 231).

De este modo, tanto la cosmovisión del protagonista como los ambientes y la estructura de la acción narrativa nos comunican que los medios de comunicación y la publicidad reafirman el modo de pertenencia a un sistema de producción y consumo crecientes que, supuestamente, ofrece el camino más corto hacia la felicidad absoluta. La ideología dominante, controlada en el relato por los alienígenas, articula todos los mensajes mediáticos de la sociedad descrita. Todo objeto contiene mensajes publicitarios intrínsecos. Los anuncios publicitarios se muestran como lo que son, publicidad. Pero más allá de su mensaje individual (con tal coche te sentirás más seguro, realizando tal viaje podrás sentirte más feliz), todo relato publicitario esconde 
mensajes cortos, fáciles de comprender, encubiertos por otros mensajes que distraen la atención; y todos son mensajes que le dicen a la gente que ha de comprar cada vez más, gastar dinero, puesto que esa práctica es la que le hará sentir bien. En cualquier caso, el dispositivo ideológico siempre permanece oculto. Sin las gafas, la retroalimentación del sistema está asegurada, no existe alternativa, no hay otro posible sistema que favorezca la armoniosa convivencia. La constante reiteración de mensajes subliminales, que son alertas sobre el modo en que la gente ha de comportarse naturalmente, posibilita que los individuos obtengan una cosmovisión que actúa de barrera para el cambio de modelo sociocultural.

El tono satírico es constante en toda la película, lo cual nos habla de una ineludible crítica al sistema por parte de Carpenter, su director y guionista. No podemos obviar la animadversión que siente Carpenter hacia los actores principales del sistema de producción y consumo propios del capitalismo extremo incipiente que vive Estados Unidos en los años ochenta, un sistema que se asumirá como normal en los años posteriores (Sampons, 2011: 61). No obstante, el tono satírico lleva implícita una crítica feroz a todo producto comercial. De hecho, They Live se realizó con un presupuesto bajo, sobre todo comparado con las grandes producciones de Hollywood. De modo que el film muestra cómo los individuos de hoy día son el target para los estratos dominantes, quienes, a su vez, representan los valores del capitalismo exacerbado. Estos actores garantes del sistema se afanan para generar significados que se adhieren a productos, servicios e incluso a los propios individuos. Los mensajes alienígenas, que son los mensajes de la clase dominante, se convierten en leyes naturales, a través del mecanismo de la ideología. Se trata de una especie de "fetichismo de la mercancía", como ya explicara Marx (2010: 43-102), un producto ideológico que posibilita que las relaciones entre humanos se revelen como relaciones entre cosas, como intercambios constantes que se llevan a cabo mediante el dinero, ese gran fetiche.

Todos los movimientos de los humanos son comportamientos comerciales que se desarrollan de un modo natural, casi por inercia social, lo que los convierte en cultura. Y todo se produce gracias a la ideología hegemónica, neoliberal o capitalista. Así que, como se puede observar, la posible crítica de los individuos queda anulada por el propio sistema, que se encarga de que el consumismo y, por ende, la producción exponencial de productos y servicios sean asumidos como el modo de vida natural. $\mathrm{Y}$ en este entramado, los poderes estatales y empresariales son percibidos como entes que garantizan el supuesto bien común. Porque la jerarquización de los distintos estratos sociales, aunque se presenta como una realidad, también es admitida como algo natural. They Live pone de manifiesto que las diferencias sociales efectivas son tapadas con los mensajes de distracción publicitarios y de los medios de comunicación. En el mejor de los casos, dicha discriminación es aceptada como necesaria para el buen funcionamiento social. De tal forma que la publicidad y el sistema de consumo que sustenta dan lugar a grupos de personas con pensamientos y comportamientos homogéneos, mucho más dóciles y moldeables. En realidad, la película está hablando continuamente del concepto de sociedad como audiencia-masa, una estructuración sociocultural con una mayor 
carga de estandarización y mucho más homogénea que lo que propone el concepto de clase.

Los alienígenas, quienes acumulan la mayor parte del capital, reafirman la idea de que ya no existen clases sociales, ya que el funcionamiento de la sociedad se fundamenta en la idea de libertad. Pero esa peculiar idea de libertad únicamente deja decidir a los humanos entre unas pocas opciones que siempre se encuadran dentro del sistema de producción y consumo ascendentes. De nuevo, la mejor herramienta para la difusión de estas ideas es la publicidad; no podemos olvidar que en la película cualquier discurso mediático es necesariamente publicitario. En este ambiente, los conceptos de democracia y de igualdad se asumen sin más, sin un pensamiento crítico que defina dichos conceptos.

Como ya se ha explicado, la herramienta para perpetuar el sistema es la publicidad. Sin embargo, es la ideología la munición que carga esa arma, cuyo objetivo es someter a los débiles individuos. En este caso, la debilidad es una característica que se encuentra en cualquier humano, ya que toda persona es reducida a una marioneta por la acción publicitaria de una clase dominante, ese conjunto cohesionado de alienígenas que tiene una posición hegemónica dentro del engranaje sociocultural. Como explica Marcuse, "la libre elección de amos no suprime ni a los amos ni a los esclavos" (1985: 37). Y la ideología, como elemento vertebrador del sistema, se utiliza para producir cohesión social. Esto lo vive en sus propias carnes el protagonista, John Nada, y posteriormente su amigo Frank Armitage, quienes verán cómo el resto de humanos defienden el statu quo engendrado por los extraterrestres capitalistas.

Las gafas son el elemento crítico, el medio a través del cual los protagonistas tienen la posibilidad de percatarse de la equivocación en la que estaban sumidos. La sensación de cohesión social es una patraña más del sistema creado por los alienígenas que presuntamente han sido elegidos libremente por la mayoría. Siguiendo las aportaciones de Marcuse, "la reproducción espontánea, por los individuos, de necesidades sobreimpuestas no establece la autonomía; sólo prueba la eficacia de los controles" (1985: 38). Así que todos los mensajes que parten de la clase dominante han de vestirse de realidad natural. Esta es la condición necesaria de cualquier comunicación hegemónica, que es siempre publicitaria dentro de la trama. Tal y como nos cuenta Zizek (2012), la ideología no se nos impone simplemente, la ideología es nuestra relación espontánea con el entorno social y cómo percibimos cada significado. En cierta medida, la mayoría de individuos disfrutan su ideología, porque salir de ella provoca dolor. Habría que esforzarse para salir de la ideología dominante. "Esta es una paradoja que tenemos que aceptar. La extrema violencia de la liberación. Si confías simplemente en tu espontáneo sentido del bienestar, nunca conseguirás ser libre. La libertad duele" (Zizek, 2012).

\section{CONCLUSIONES}

La película They Live se configura como una crítica a la sociedad contemporánea, sustentada por una cultura económica de la producción y el consumo crecientes. Los 
individuos experimentan vidas homogeneizadas por el efecto de los mensajes publicitarios que lanzan los alienígenas que han colonizado la Tierra para esquilmarla. En este ambiente, los extraterrestres representan a las clases dominantes de nuestro mundo; grupos de personas poderosas que ostentan importantes cargos dentro de las mayores empresas privadas y de los organismos públicos. Para estos grupos hegemónicos, su herramienta principal para adormecer a la población es la publicidad, que impregna incluso cualquier mensaje de los medios de comunicación, incluyendo los informativos. No obstante, todo relato publicitario utiliza el proceso ideológico de ocultación.

John Carpenter desarrolla una crítica ácida de la sociedad consumista e individualista. Muestra las miserias cotidianas y las desigualdades propias de las llamadas sociedades de la abundancia. John Nada representa a los ciudadanos que sufren los males endémicos actuales: el paro, la pobreza, el difícil acceso a la vivienda. Las gafas, que ayudan a desenmascarar a los alienígenas y a percibir claramente cuáles son sus intenciones, son el elemento que aporta el sentido crítico. En el momento en que Nada utiliza las gafas, que representan el espíritu crítico y la capacidad reflexiva, se convertirá en un disidente sociocultural. Ponerse las gafas supone destapar la dictadura de nuestras democracias actuales, según Carpenter. La libertad es un hecho aparente amparado por un orden invisible.

Los grupos sociales que acumulan la mayoría del capital, que son una minoría en realidad, utilizan la publicidad para crear consenso entre la mayoría ciudadana. Los grupos hegemónicos usan los mensajes publicitarios para generar una sensación de cohesión social. Mediante los mensajes persuasivos del consumo, los poderosos, representados por los alienígenas, imponen su cosmovisión y obligan en cierta forma a seguir una cultura determinada; es decir, los grupos hegemónicos utilizan los mensajes publicitarios para provocar pensamientos y conductas homogéneos en torno a la idea del consumo exacerbado, que implica una producción creciente capaz de provocar la destrucción del planeta.

Sin embargo, John Nada no está solo, como se muestra en la película. El protagonista irá encontrando a más personas disidentes escondidas durante el desarrollo de la trama, sujetos que han descubierto el truco de las gafas, como le ocurre a su amigo Frank Armitage. Aunque los opositores son una minoría, todos ellos están caracterizados por el activismo férreo contra las clases dominantes. Ello pone de relieve, grosso modo, que en la actualidad existen dos estratos minoritarios y uno mayoritario. Los dos estratos minoritarios son los dominadores y los parias críticos. El grupo mayoritario está compuesto por la mayoría ciudadana cuyo pensamiento y conducta están tamizados por la acción ideológica; esos individuos seducidos por los sueños publicitarios de la abundancia, de la acumulación del capital y por el individualismo. Esa audiencia-masa aún no ha percibido lo que se esconde detrás de las acciones propias del sistema consumista en el que se desenvuelven, aún no se han 
puesto las gafas. Aún así, Carpenter intenta comunicar que existe la posibilidad de que surjan movimientos sociales y culturales subalternos capaces de actuar en contra de las prácticas totalitarias y antiecológicas del mundo capitalista.

\section{REFERENCIAS}

Arens, W.; Weigold, M. \& Arens, C. (2008). Publicidad. México: McGraw-Hill.

Bordwell, D. (1995). El significado del filme. Inferencia y retórica en la interpretación cinematográfica. Barcelona: Paidós.

Eguizábal, R. (2009). Industrias de la conciencia. Una historia social de la publicidad en España (1975-2009). Barcelona: Península.

Ewen, S. \& Ewen, E. (1982). Channels of Desire: Mass Images and the Shaping os American Consciousness. New York: McGraw-Hill.

Franco, L. J. (productor) \& Carpenter, J. (director). (1988). They Live [cinta cinematográfica]. Estados Unidos: Alive Films.

García-López, J. \& Hellín, P. (2014). Cronotopos y estereotipos de la ficción publicitaria. Un análisis sobre la identificación del receptor con el relato publicitario, en Historia y Comunicación Social, vol. 19. Págs. 759-769.

Grupo Marcuse (2009). De la miseria humana en el medio publicitario. Cómo el mundo se muere por nuestro modo de vida. Barcelona: Melusina.

Hellín, P. A. (2007): El uso de los valores sociales en la comunicación publicitaria: la socialización corporativa, en Pensar la Publicidad, vol. 1, nº 1. Págs. 157-180.

Hirschman, E. C. (2003). Men, Dogs, Guns, and Cars. The Semiotics of Rugged Individualism, en Journal of Advertising, vol. 32, nº 1. Págs. 9-22.

Ibáñez, J. (1989): Publicidad: la tercera palabra de Dios, en Revista de Occidente, no 92. Págs. 73-96.

Lipovetski, G. \& Serroy, J. (2009). La pantalla global. Cultura mediática y cine en la era hipermoderna. Barcelona: Anagrama.

Marx, K. (2010). El capital. Crítica de la economía politica. Antología (selección, introducción y notas de César Rendueles). Madrid: Alianza. 
Marcuse, H. (1985). El hombre unidimensional. Ensayo sobre la ideología de la sociedad industrial avanzada. Barcelona: Planeta-Agostini.

McKee, R. (2002). El guión. Sustancia, estructura, estilo y principios de la escritura de guiones. Barcelona: Alba.

Polanyi, K. (2014). Los límites del mercado: reflexiones sobre economía, antropología y democracia. Madrid: Capitán Swing.

Riechmann, J. (2014). Un buen encaje en los ecosistemas. Segunda edición (revisada) de Biomímesis. Madrid: Los libros de la Catarata.

Sampons, J. (2011). John Carpenter, llegenda viva del cinema fantàstic, en Quadern de les idees, les arts i les lletres, nº 189. Págs. 61-63.

San Nicolás, C. (2006): "Publicidades" de lo cotidiano: una visión comunicativa de la cultura como encrucijada, en Comunicación: Revista Internacional de Comunicación Audiovisual, Publicidad y Estudios Culturales, no 4. Págs. 179-192.

Sánchez-Escalonilla, A. (2009). Fantasía de aventuras: La exploración de universos fantásticos en literatura y cine, en Comunicación y Sociedad, vol. XXII, nº 2. Págs. 109137.

Scott, L. M. (1994): Images in Advertising: The Need for a Theory of Visual Rhetoric, en Journal of Consumer Research, vol. 21. Págs. 252-273.

Swires, S. (1988). John Carpenter and the Invasion of the Yuppie Snatchers, en Starlog, $\mathrm{n}^{\mathrm{o}}$ 136. Págs. 37-40.

Thompson, J. B. (1988). Mass Communication and Modern Culture: Contribution to a Critical Theory of Ideology, en Sociology, vol. 22, nº 3. Págs. 359-383.

Truby, J. (2009). Anatomía del guión. El arte de narrar en 22 pasos. Barcelona: Alba.

Weil, P. (1992). La comunicación global. Barcelona: Paidós.

Williamson, J. (1978): Decoding Advertisements: ideology and meaning in advertising. London: Marion Boyars.

Zizek, S. (2012). The Pervert's Guide to Ideology [documental]. Reino Unido: P. Guide Productions. 


\section{AUTOR:}

\section{Javier García López:}

Doctor en Comunicación, máster universitario en Crítica y Argumentación Filosófica, especialista en Epistemología y Gnoseología, especialista en Comunicación Institucional y licenciado en Publicidad y RR.PP. Desde 2010 es Profesor Contratado Doctor en la Universidad a Distancia de Madrid. Ha sido profesor en la Universidad San Jorge y ha trabajado para los ministerios de Presidencia y Asuntos Exteriores. Es autor de diversos artículos y capítulos de libro científicos y académicos. Colabora habitualmente en diferentes diarios y en televisión (La Aventura del Saber, TVE), donde ofrece de un modo divulgativo sus investigaciones. Es autor de los libros Publicidad y marketing (Editorial CEF), Publicidad. Teoría y práctica (Editorial CEF), Publicidad. Comunicación y cultura (Editorial UOC) y Dispublicitados. Los efectos (ideológicos) de la publicidad (Editum).

ORCID: orcid.org/0000-0002-7306-4289 - ResearcherID: C-9191-2011 